\title{
Infections and paraneoplastic disorders in patients with solid malignancies of advanced clinical stage
}

\author{
Géza Bozóky* and Éva Ruby \\ Department of Pulmonology, Hospital of Bács-Kiskun County Municipality, Kecskemét, Hungary
}

\begin{abstract}
The prevalance of disorders of infectious and paraneoplastic origins in 750 patients with solid malignancies of advanced clinical stage in various locations has been reviewed by the authors in the period from 2009 to 2019. Of the infections, pneumonia and acute exacerbation of COPD occurred most frequently. Based on the observations of the authors, it has been assessed that the bacterial infections in cancer patients are very frequently associated with severe symptoms and often lead to sepsis. Paraneoplastic disorders occurred in cancers patients very frequently. These are primarily the disorders of the haematological system and the haemostasis. Of the metabolic disorders, hyponatraemia was predominant and had a significant negative affect on the quality of life of the patients. Additionally, both in number and nature, several disorders were observed related to gastrointestinal diseases, renal involvement, autoimmune processes, and endocrine disorders.
\end{abstract}

\section{Introduction}

In patients with advanced clinical stage solid malignancies, the complex management, which is in line with professional guidelines and patient expectations, is often a major challenge for both the physicians and the nursing staff. The disease progression in cancer patients may occur due to the local and/or systemic spread of the primary malignancy, even though, all possible active oncological treatment options were tried. The symptoms of clinical progression occur upon the manifestation of infections primarily involving the lungs and the kidneys. Paraneoplastic disorders, which develop in direct or indirect association with malignancies, have a marked impact on the quality of life and life expectancy of patients. They can trigger multi-organ dysfunction syndrome and disorders. In the case of advanced malignancies, beyond the paraneoplastic disorders, it is not uncommon that pathological processes (such as acute gastrointestinal bleeding, acute pancreatitis) that cannot be associated with the primary malignancy also develop.

\section{Patients and methods}

The majority of the 750 patients with malignancy of advanced clinical stage (Table 1) assessed in the period of 10 years (from 2009 to 2019) was classified as elderly. The majority of patients $(n=490)$ had primary lung cancer, predominantly non-small-cell lung carcinoma (NSCLC). A large number of patients were identified as having colorectal or breast cancer, and a smaller number of patients had malignancies of renal, ovarian, gastric and hepatobiliary origin (Table 2). Of the 750 patients, staging examinations confirmed locally advanced clinical stage in 640 cases (Table 3 ). In addition to the locally advanced disease $(\mathrm{n}=304)$, a similar number of multiple organ (lymphatic) metastases $(n=336)$ has also been detected. The development of bacterial infections was detected in 378 patients (Table 4). Pneumonia was confirmed in 152 cases radiologically or by chest CT scan, and acute exacerbation of COPD was confirmed in 124 patients. The incidence of septic processes is notable $(\mathrm{N}=78)$, most certainly as an immune-related adverse effect of the previously administered cytotoxic chemotherapy or radiation therapy. The types and incidences of paraneoplastic disorders, directly or indirectly associated with malignancies are summarised in Tables 5 and 6 . Of the paraneoplastic disorders, the disorders of the haematological system and the haemostasis occurred most frequently in cancer patients. A large number of patients had metabolic $(n=529)$, cardiac $(n=417)$ and gastrointestinal $(n=317)$ disorders, while kidney, immunological and endocrine disorders affected a smaller number of patients [1-13].

Table 1. General characteristics of the patients with solid carcinoma

\begin{tabular}{|c|c|}
\hline Period reviewed & $\mathbf{2 0 0 9 - 2 0 1 9}$ \\
\hline Number of cases & $\mathrm{n}=750$ \\
\hline Male & $\mathrm{n}=410$ \\
\hline Female & $\mathrm{n}=340$ \\
\hline Age & 48 to 79 years \\
\hline Mean age & 61 years \\
\hline
\end{tabular}

Table 2. Classification of tumorous processes based on localisation

\begin{tabular}{|c|c|}
\hline $\begin{array}{c}\text { Tumour location } \\
\text { Primary lung cancer } \\
\text { NSCLC: } \mathbf{n}=\mathbf{3 8 6} \\
\text { SCLC: } \mathbf{n = 1 0 4}\end{array}$ & $\begin{array}{c}\text { Number of cases (n) } \\
\mathbf{4 9 0}\end{array}$ \\
\hline Colorectal & 65 \\
\hline Breast & 82 \\
\hline Gastric & 16 \\
\hline Hepatobiliary & 26 \\
\hline Kidney-urinary bladder & 36 \\
\hline Ovarian & 29 \\
\hline Malignant melanoma & 6 \\
\hline
\end{tabular}

${ }^{\star}$ Correspondence to: Géza Bozóky, Department of Pulmonology, Hospital of BácsKiskun County Municipality, Kecskemét, Hungary, E-mail: bozokyg@freemail.hu

Key words: advanced-stage malignancy, severe infection, paraneoplastic disorders, multi-organ dysfunction syndrome

Received: August 01, 2020; Accepted: August 14, 2020; Published: August 19, 2020 
Table 3. Dissemination of the disease

\begin{tabular}{|c|c|}
\hline Type of localisation & Number of patients (n) \\
\hline Locally advanced disease & 304 \\
\hline Multiple organ metastases & 218 \\
\hline Lymphatic involvement & 118 \\
\hline $\begin{array}{c}\text { Severe non-cancerous disease } \\
\text { (heart, lung, kidney, metabolic diseases) }\end{array}$ & 100 \\
\hline
\end{tabular}

Table 4. Infectious diseases

\begin{tabular}{|c|c|}
\hline Type of infection & Number of cases \\
\hline Acute pneumonia & 152 \\
\hline Acute exacerbation of COPD & 124 \\
\hline Acute pyelonephritis & 22 \\
\hline Sepsis & 78 \\
\hline Necrotising fasciitis & 2 \\
\hline
\end{tabular}

Table 5. Paraneoplastic disorders in our cancer patients

\begin{tabular}{|l|c|}
\hline \multicolumn{2}{|c|}{ Haematological disorders } \\
\hline The type of abnormalities & Number of patients \\
\hline Anaemia $(\mathrm{Hgb} \leq 100 \mathrm{~g} / \mathrm{L})$ & 335 \\
\hline Leukopaenia $\left(\right.$ leukocyte count $\left.\leq 1.5 \times 10^{9}\right)$ & 69 \\
\hline Leukocytosis (leukocyte count $\left.\geq 10.8 \times 10^{9}\right)$ & 48 \\
\hline Thrombocytopaenia (platelet count $\left.\leq 80 \times 10^{9} / \mathrm{L}\right)$ & 6 \\
\hline Autoimmune haemolytic anaemia & 2 \\
\hline Pure red-cell aplasia & 116 \\
\hline & 108 \\
\hline Thrombophlebitis (superficial) & 79 \\
\hline Acute deep vein thrombosis & 4 \\
\hline Acute pulmonary embolism & 2 \\
\hline Acute disseminated intravascular coagulation & \\
\hline Thrombotic thrombocytopenic purpura & Number of cases \\
\hline Gastrointestinal disorders & 89 \\
\hline The type of abnormalities & 45 \\
\hline Acute gastrointestinal bleeding & 172 \\
\hline Acute pancreatitis & 12 \\
\hline Hepatic dysfunction of various severities & \\
\hline Acute mesenteric ischaemia & \\
\hline
\end{tabular}

\section{Discussion}

Paraneoplastic disorders and infections, frequently developing in cancer patients of advanced clinical stage, are of notable importance in terms of the quality of life of patients and adversely affect life expectancies. Timely identification of the extremely complex paraneoplastic disorders associated with different organ manifestations is of essential importance, otherwise no effective treatment can be ensured. The recognition of symptoms is impeded by the fact that often multiple paraneoplastic disorders develop simultaneously, and the identification of the less evident abnormalities related to dominant symptoms is delayed. The large number of paraneoplastic disorders demonstrates that solid malignancies include not only the disorder of the affected organ but also affect the physical and mental status of the entire body, i.e. a malignancy of any stage can be considered systemic in every case. Often, the development of paraneoplastic symptoms cannot be explained by the local invasion and/or metastasis (metastases) of the tumour: they are rather the result of the abnormal hormone, protein or cytokine production of the tumour $[5,7,12]$. The role of the immune response of the body can be considered and often confirmed too: primarily, tumour antigens in the different tumour tissues can induce an immune response, and as a consequence inflammation may develop even in the otherwise intact tissues [5]. In the case of paraneoplastic syndromes the clinical symptoms are similar to those of primary endocrine, dermatological, rheumatological, haematological and neuromuscular diseases $[5,12,13]$.

In addition to the development of paraneoplastic disorders, the occurrence of bacterial infections is also of great importance. Inflammation induced by bacterial infection has been identified in nearly $50 \%(n=378)$ of the assessed 750 cancer patients in advanced stage. The most common inflammations were the development of pneumonia $(n=152)$ and acute exacerbation of COPD $(n=124)$. A large number of septic complications occurred $(n=78)$ and in these patients septic fever, marked leukocytosis, blood test - left shift, highly elevated CRP, and positive procalcitonin test were observed. In the majority of cases, chest radiography and chest CT scans confirmed very severe inflammations with pleural effusion and frequent cavitation of the infiltrative lesions. Severe pyuria, highly elevated CRP, and septic symptoms were frequently noticed in inflammatory processes involving the kidneys.

Of the paraneoplastic disorders, haematological disorders were predominant in our patients $(\mathrm{n}=551)$ (Table 5). Of the haematological disorders, anaemia occurred most frequently $(n=335)$, nearly $30 \%$ of the cases were iron deficiency anaemia and nearly $10 \%$ of the cases were $\mathrm{B} 12$ and folic acid deficiency anaemia. Anaemia induced by bone barrow infiltration of the malignant cells was observed in $8 \%$ of our cases. The

Table 6. Paraneoplastic disorders in cancer patients

\begin{tabular}{|c|c|}
\hline \multicolumn{2}{|c|}{ Cardiac disorders } \\
\hline The type of abnormality & Number of patients (n) \\
\hline $\begin{array}{l}\text { Congestive heart failure } \\
\text { (Systolic left ventricular dysfunction) }\end{array}$ & 144 \\
\hline Ischaemic heart failure & 126 \\
\hline Tachyarrhythmia with atrial fibrillation & 98 \\
\hline Pericardial effusion & 29 \\
\hline \multicolumn{2}{|c|}{ Metabolic disorders } \\
\hline The type of abnormality & Number of cases (n) \\
\hline Hyperglycaemia & 98 \\
\hline Hyperglycaemia with ketoacidosis & 69 \\
\hline Hyperuricaemia & 179 \\
\hline Hypercalcaemia & 49 \\
\hline Type-B lactic acidosis & 12 \\
\hline Hyponatraemia (SIADH) & 183 \\
\hline Hypoglycaemia & 49 \\
\hline \multicolumn{2}{|c|}{ Renal involvement } \\
\hline Disorders & Number of cases (n) \\
\hline Acute pyelonephritis & 49 \\
\hline Acute pyelonephritis with sepsis & 26 \\
\hline Acute renal failure & 53 \\
\hline Asymptomatic proteinuria/microhaematuria & 68 \\
\hline Renal vein thrombosis & 2 \\
\hline \multicolumn{2}{|c|}{ Autoimmune disorders } \\
\hline Diagnoses & Number of cases (n) \\
\hline $\begin{array}{l}\text { Rheumatoid-like arthritis } \\
\text { (acute polyarthritis) }\end{array}$ & 52 \\
\hline Immune hepatitis & 4 \\
\hline Pleuritis-pneumonitis & 34 \\
\hline Acute pericarditis & 28 \\
\hline Dermatomyositis & 2 \\
\hline \multicolumn{2}{|c|}{ Endocrine disorders } \\
\hline Diagnoses & Number of cases (n) \\
\hline Adrenal cortex insufficiency (Addison's disease) & 16 \\
\hline Hypothyroidism & 10 \\
\hline Hyperthyroidism & 12 \\
\hline
\end{tabular}


frequency of quantitative leukocyte and platelet abnormalities was nearly $20 \%$. Immune haemolytic anaemia and pure red-cell anaemia was confirmed in six and two patients, respectively.

Haemostatic disorders were also often diagnosed (Table 5). In addition to superficial (in several cases migratory) thrombophlebitis, 178 cases of acute deep vein thrombosis and acute pulmonary embolism occurred. It is noteworthy that $50 \%$ of the manifestation of the acute pulmonary embolism cases were asymptomatic ("silent"), primarily in patients with primary pulmonary malignancy $[3,11]$.

Of the gastrointestinal and hepatobiliary disorders, 89 cases of acute gastrointestinal bleeding and 172 cases of hepatic disorder of various degrees of severity were observed. Cases of acute pancreatitis and acute mesenteric ischemia also occurred. The presence of liver metastases was the primary cause of abnormal liver functions; hepatic lesions of toxic origin, cholangitis and cholangiosepsis occurred more rarely.

A significant proportion of cardiac disorders cannot be directly attributed to malignancies. However, of the 29 patients with pericardial effusion, the development thereof was clearly related to the malignant process (pericarditis carcinomatosa) in 18 cases. Systolic left ventricular dysfunction, ischaemic heart disease, and tachyarrhythmia with atrial fibrillation were observed most frequently.

Of the metabolic disorders, 98 cases of hypercalcaemia and 69 cases hyperglycaemia with ketoacidosis were observed. Prolonged glucocorticoid therapy, infections, immunosuppressive therapy, repeated transfusions and cachexia predispose to the aforementioned conditions. In cancer patients under treatment, hyperuricaemia develops often, sometimes concomitantly with hypercalcaemia and hyperphosphataemia $[8,9,13]$. The acute tumour lysis syndrome occurs rarely in patients with solid malignancies, and rather develops in patients under therapy for acute haemoblastoses or malignant lymphomas. Type-B lactic acidosis occurs rarely and its exact cause is unclear but mainly the tissue hypoperfusion due to microemboli caused by circulating tumour cells, and the increased anaerobic metabolism triggered by this can lead to acidosis [13]. The development of hyponatraemia is a very common and severe metabolic disorder in solid malignancies [9]. Acute, severe hyponatraemia may cause nausea, vomiting, headache, severe muscle weakness, generalised seizures, and coma. The syndrome of inappropriate antidiuretic hormone secretion (SIADH) is characterised by hypo-osmotic euvolemic hyponatraemia $(134 \mathrm{~m} \mathrm{Egr} / \mathrm{L})$ and increased urine osmolality $(100 \mathrm{mOsm} / \mathrm{kg})$. In cancer patients this syndrome arises from tumour cell production of antidiuretic hormone (ADH: arginine vasopressin), and atrial natriuretic peptide [13].

Kidney lesions did not occur frequently in our patients. Inflammatory processes were predominant. Acute kidney failure mainly occurred due to acute disseminated intravascular coagulation, haemolytic anaemia and thrombotic thrombocytopenic purpura. The use of antineoplastic medicinal products can be complicated by acute renal failure, and sepsis and renal infiltration of malignant cells should be considered as predisposing factors [6,7]. Asymptomatic proteinuria and microhaematuria without abnormal kidney functions were observed in 68 patients. It is well known from clinical experience that the properly functioning immune system has a protective role against the development of malignancies. In severe immunodeficiencies ("immunocompromised" states), both solid malignancies (breast, prostate, lung, colon, ovarian) and oncogenic viral (herpesvirus type 8, and Epstein-Barr virus) infection-related diseases Kaposi's sarcoma and B-cell non-Hodgkin's lymphoma develop more frequently [5]. Autoimmune conditions are primarily caused by autoantibody production against tumour cells (tumour antigens). These autoantibodies can induce immunological disorders in different organs (joints, lungs, serous membranes, skeletal muscles, kidneys) $[1,2,5]$. In our cases, symptoms of polyarthritis were predominant, $(n=52)$ (Table 6). Severe dermatomyositis was observed in two patients with renal tumour. Cases of serositis were observed in 62 patients.

Of endocrine disorders, adrenal insufficiency, hypothyroidism and hyperthyroidism occurred in 16,10 and 12 patients, respectively. Of the neurological disorders, peripheral neuropathy was observed in 8 patients with small-cell lung cancer. (Lambert-Eaton syndrome) [12].

\section{References}

1. Azar I, Khasnis A (2013) Paraneoplastic rheumatologic syndromes. Curr Opin Rheumatol 25: 44-49.

2. Bojinka V, Janta I (2012) Rheumatic diseases and malignancies. Medica I Clin Med 7: $364-371$.

3. Bozóky G, Ruby É (2018) Acute silent non-massive (submassive) pulmonary embolism. Am I Ang and Surg 1: 001-003.

4. Carella A, Marinelli T, Pumpo M, Benvenuto E (2015) Metabolic disorders in hematologic malignancies-A review. Archives of Medicine 7: 1-8.

5. Prakash O, Gill J, Farr G (2002) Immune disorders and susceptibility to neoplasms. Ochsner J 4: 107-111. [Crossref]

6. Humphreys BD, Soiffer RJ, Magee CC (2005) Renal failure associated with cancer and its treatment: an update. J Am Soc of Nephrol 16: 151-161. [Crossref]

7. Darmon M, Ciroldi M, Thiery G, Schlemmer B, Azoulay E (2006) Clinical review Specific aspects of acute renal failure in cancer patients. Crit Care 10: 211. [Crossref]

8. Maesaka JK, Imbriano L, Mattana J, Gallagher D, Bade N, et al. (2014) Differentiating SIADH from cerebral renal salt wasting: failure of the volume approach and need for a new approach to hyponatraemia. J Clin Med 3: 373-385. [Crossref]

9. Verbalis JG, Goldsmith SR, Greenberg A, Korzelius C, Schrier RW, et al. (2013) Diagnosis, evaluation, and treatment of hyponatraemia: expert panel recommendations. Am J Med 126: 91-47. [Crossref]

10. Bozóky G (2019) Community-acquired pneumonia as a cause of sepsis. Trends Med 19: $1-4$.

11. Bozóky G (2007) Disorders of the haemostatic system in patients with solid malignances. In: Handbook of hematology. Editors: Tondre C, Lebéque C, pp: 317-318.

12. Bataller Dalman J (2003) Paraneoplastic neurologic syndromes: approaches to diagnosis and treatment. Semin Neurol 23: 215-224.

13. Androgue HJ, Madias NE (2000) Hyponatraemia. N Eng J Med 342: 1581-1589.

Copyright: (C2020 Bozóky G. This is an open-access article distributed under the terms of the Creative Commons Attribution License, which permits unrestricted use, distribution, and reproduction in any medium, provided the original author and source are credited. 